Research Article

\title{
A Study of Health Information Search Behaviour and Its Application among Young Adults
}

\author{
Deepa Makesh', Sandhya Rajasekhar ${ }^{2}$ \\ ${ }^{1}$ Research Scholar, School of Communication and Media Studies, M.O.P. Vaishnav College for Women (Autonomous) Chennai, \\ India. \\ ${ }^{2}$ Associate Professor \& Head, Department of Journalism, School of Communication and MediaStudies, M.O.P. Vaishnav College \\ for Women (Autonomous) Chennai, India.
}

DOI: https://doi.org/10.24321/2349.2880.202001

\section{I $\quad \mathbf{N} \quad \mathbf{F} \quad \mathbf{O}$}

\section{Corresponding Author:}

Sandhya Rajasekhar, Department of Journalism, School of Communication and MediaStudies, M.O.P. Vaishnav College for Women (Autonomous) Chennai, India.

E-mail Id:

sandhyarajasekhar@gmail.com

Orcid Id:

https://orcid.org/0000-0002-8335-9144

How to cite this article:

Makesh D, Rajasekhar S. A Study of Health Information Search Behaviour and Its Application among Young Adults. Ind J Youth Adol Health 2020; 7(1): 1-6.

Date of Submission: 2020-07-15

Date of Acceptance: 2020-07-20

\section{$\begin{array}{llllllll}\mathbf{A} & \mathbf{B} & \mathbf{S} & \mathbf{T} & \mathbf{R} & \mathbf{A} & \mathbf{C} & \mathbf{T}\end{array}$}

Health Information Seeking Behaviour (HISB) refers to the ways in which individuals seek information about their health, risks, illnesses, and health-protective behaviours. According to a survey, the most common topics of search included fitness and exercise, diet and nutrition, stress and anxiety, sexually transmitted diseases, puberty, depression and other mental health issues and sleep. The growth in the digital landscape and increase in health information has introduced a new trend among the young adults-seeking information from internet.

Health Belief Model is one of the most important models in studying influences on health beliefs on both individuals and society.

This is a study to identify media consumption patterns of young adults pertaining to health - the main areas of search, the platforms that are most commonly accessed, application of the information gathered and their existing health related values, attitudes and beliefs. Through a survey the study points out that although respondents are satisfied with health information consumed online, most of them however, do not find a positive change in health-related values and beliefs by consuming health information on media. There is a need for strong communication on health aspects.

Keywords: Health Information Search Behaviour, Media Access and Consumption, Application of Health Related Information, Health Related Values and Beliefs, Young Adults

\section{Introduction}

An adult is a person older than 19 years of age unless national law defines a person as being an adult at an earlier age. ${ }^{1}$ Cambridge dictionary define a Young adult is a person who is in his or her late teenage years or early twenties. The Society for Adolescent Health and Medicine defines young adulthood as including the age range 18-25 years.

Young adulthood is a unique and critical time of development where unmet health needs and health disparities are high. Purposeful prevention and intervention strategies should be developed, researched, and implemented during this time to improve health and well-being of young adults.

These young adults have grown up in an electronics-filled and increasingly online and socially-networked world. The internet is sought to learn about a health concerns - curative and preventive. The growth in the digital landscape and 
increase in health information has introduced a new trend among the young adults.

Currently, Health Information Seeking Behavior (HISB) is broadly viewed as the ways by which individuals obtain information about health, illness, health promotion and risks to health. ${ }^{1}$ Common sources of information include parents, friends, media. ${ }^{2}$ Mass media plays a central role in people's lives. Its importance is evident in the amount of time people spend watching television, surfing the World Wide Web, listening to music, and reading newspapers and magazines. The delivery of information through mass media is instant and available around the clock. The media can be used as the primary change agent or as a means to support other education and clinical services. The role of media may be identified as: (a) media as educator, (b) media as supporter, (c) media as program promoter, and (d) media as supplement. ${ }^{3}$ According to findings from a national survey a large number of teenagers use the Internet and consider it as a key source for information about health. ${ }^{4}$ Although teens do trust and consider their parents, school health classes and health care providers as their most common sources for information about health, the study showed that $84 \%$ had gone online to find health information. These teens are interested in varied topics related to health and according to the survey, the most common topics were fitness and exercise, diet and nutrition, stress and anxiety, sexually transmitted diseases, puberty, depression and other mental health issues, and sleep.

The Internet offers widespread access to health information, with the advantages of interactivity, information modifying, and anonymity. It enables individuals to control their own care, choose health providers, and feel empowered. It also helps in improving the interactions between patients with the health professionals. Internet use for health information might improve individual's belief that what they are finding might be having an impact on their health.

Hence this study aims to identify media consumption patterns of young adults pertaining to health-the main areas of search, the platforms that are most commonly accessed, application of the information gathered and their existing health related values, attitudes and beliefs.

\section{Objectives}

This study specifically aims to:

- Identify media consumption patterns of young adults pertaining to health.

- The main areas of search pertaining to health.

- The various platforms that are most commonly accessed for health information.

- The existing health related values and beliefs.

- Application of the health information consumed.

\section{Methodology}

\section{Study Design}

Exploratory study. Survey methodology was used to study the health information seeking behaviour, diet and fitness as variables, among young adults only.

The unit of study was a young adult in the age group 18-21 years in the city of Chennai.

\section{Study Duration}

Questionnaire was posted on google forms was open for seven days in the mid of January 2020.

\section{Inclusion and Exclusion Criteria}

The study focused only on health information search behaviour and media used for information on general health, diet and fitness.Other health issues/concerns and media/communication effects were excluded from the study design.

\section{Statistical Tool Used}

Descriptive statistics involving frequency tabulation was used for the analysis.

Pie charts and bar graphs were used to project the data.

\section{Ethical Approval}

- Not requiredDuring data collection, respondents willingly participated in the survey.

- Confidentiality of information obtained is ensured by using it for academic purposes only.

- Care was taken to avoid plagiarism.

The methodology for the study was survey with the online questionnaire as a tool. The unit of study or respondent is any young adult in the age group 18-21 years. The survey was conducted among 127 young adults in Chennai city who have an access to and are users of the Internet either with the computer or the smart phone. Sampling technique used is non-random.

\section{Ethical Consideration}

The respondents willingly participated in the survey. Confidentiality of information obtained was ensured. Personal identifiers not to be published.

\section{Result}

127 responses were got for the study for which an online questionnaire was used. A non-probability sampling was used to reach the respondents. They were approached on WhatsApp groups and asked to click on the link given and fill the form. Since only girls were sent the link, they were asked to pass on the link to at least one male in the given age group, so the study would include male respondents as well (Figure 1). 


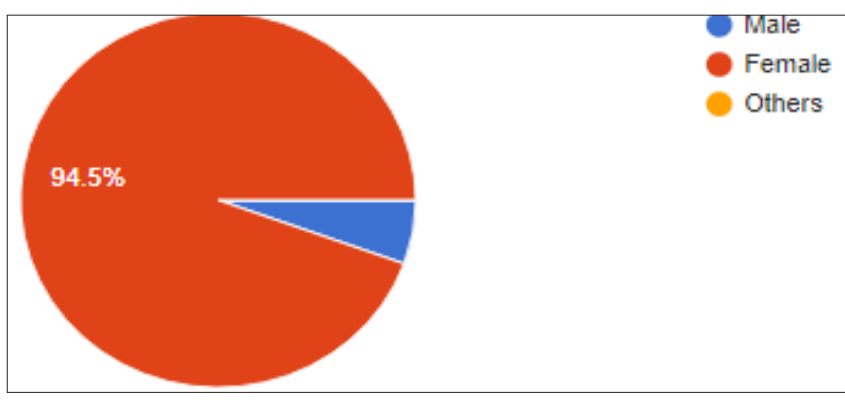

Figure I(A).Respondent profile. Male and Female respondents

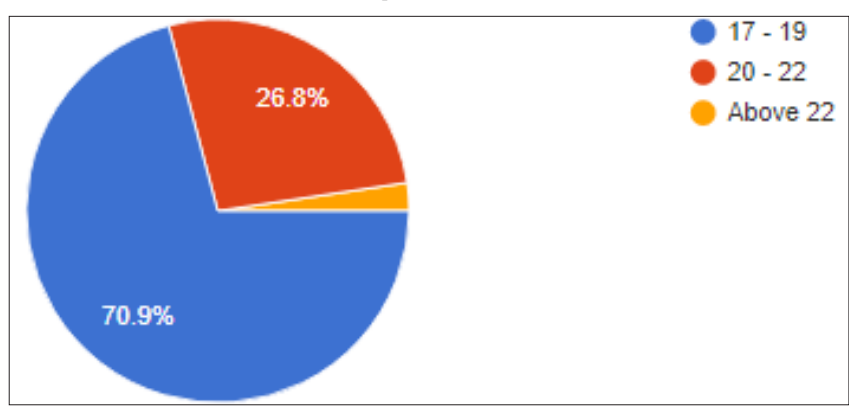

Figure I(B).Age of the respondent

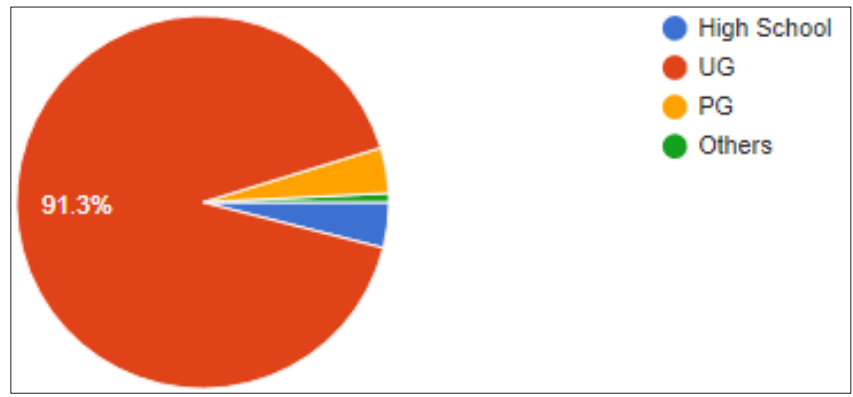

$\mathrm{N}=127$

Figure I(C).Education of the respondent

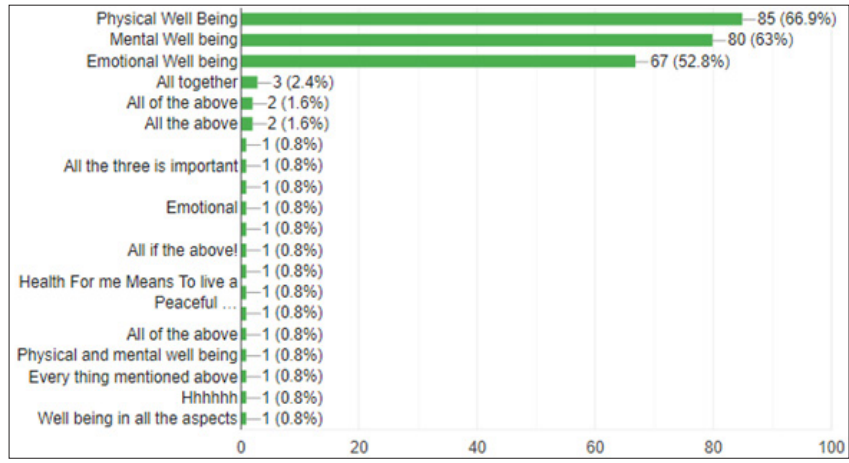

$\mathrm{N}=127$

Figure 2.Dimensions of health according to the respondent

Considering that most respondents were in the age group 17-19, it is no surprise that physical wellbeing ( 85 respondents) and mental wellbeing (80\%) were considered two important aspects of health by more than $60 \%$ of the respondents. Emotional wellbeing was also considered important by $52 \%$ of the respondents (Figure 2 ).

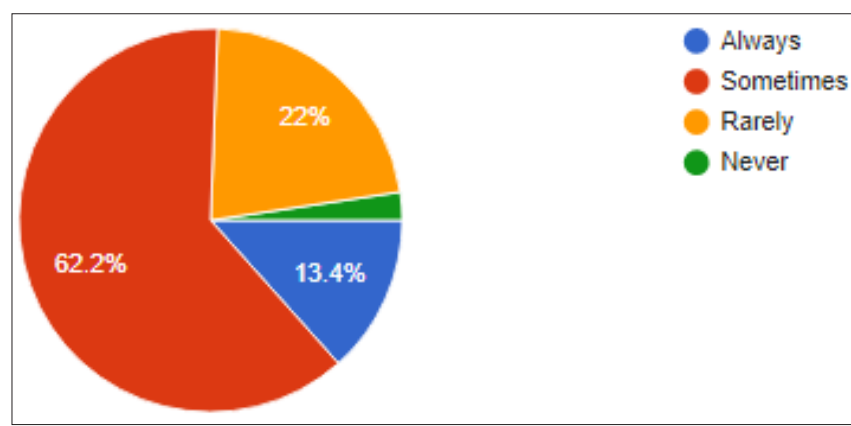

$\mathrm{N}=127$

Figure 3.Access of health information in media About 29 of them do not seek information on health (Figure 3).

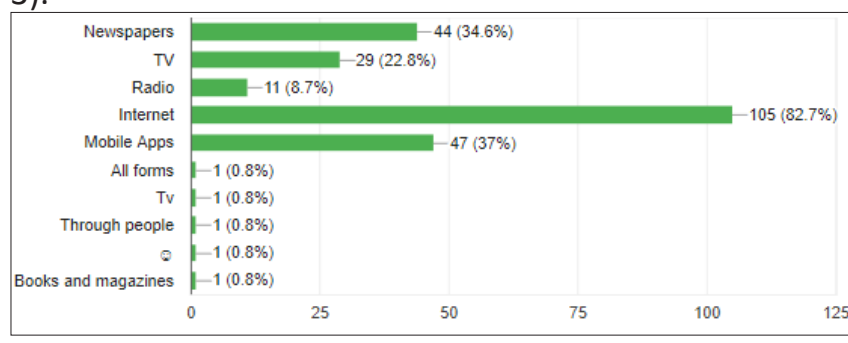

$\mathrm{N}=127 *$ (multiple choice question)

Figure 4.Media used to consume health information

The growth in the digital landscape and increase in health information has introduced a new trend among the young adults-seek information from internet. It is no surprise then, that a large number (105) of the respondents consumed health-related information from the internet. It is also interesting that mobile apps were used for such information by more respondents (37\%) than those who consumed health information from newspapers and television (Figure 4).

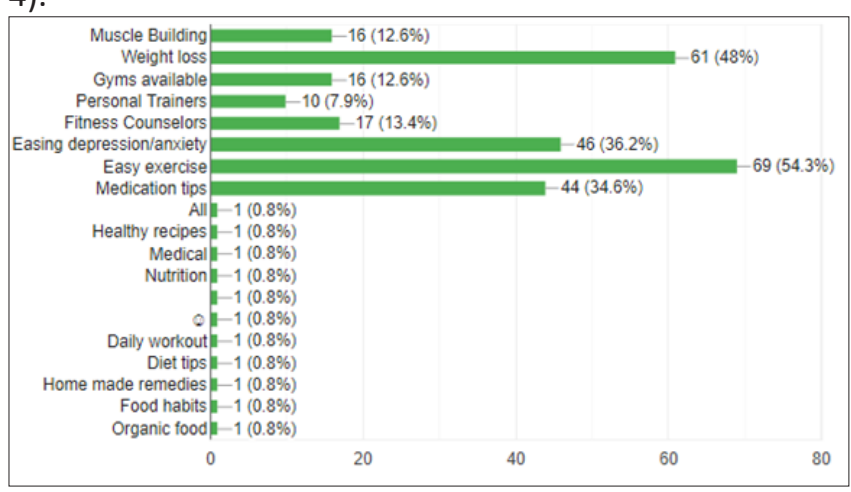

$\mathrm{N}=127$

Figure 5.Health information sought for general health and fitness

The most popular type of information sought regarding general health and fitness were easy exercise (54.3\%) and weight loss (48\%). Easing depression and anxiety is next, followed by medication tips. The credibility of such information available on the internet should be an important area of concern (Figure 5). 


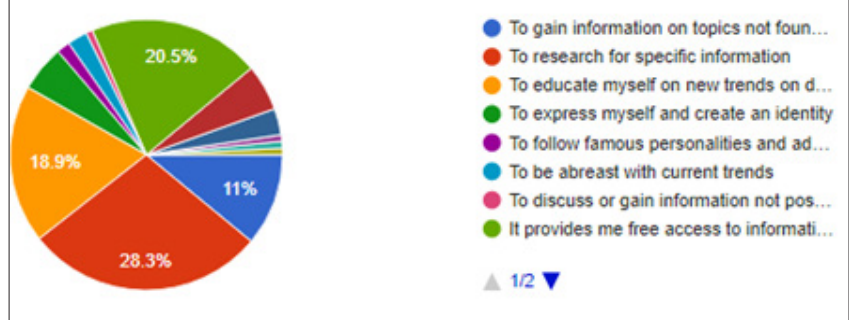

$\mathrm{N}-=127$

Figure 6.Reason for seeking/ consuming health information online

Most of the respondents went online for health information to research for specific information. Interestingly, the gratification goes beyond being informed. $20.5 \%$ consumed health information to express oneself and create an identity (Figure 6).

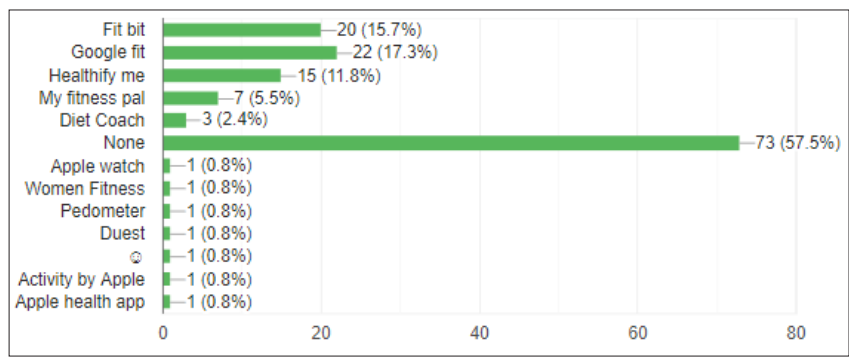

$\mathrm{N}=127$

Figure 7.Use of mobile health apps for health information seeking regarding diet

Most of the respondents did not use any health-related apps. Apps still have a long way to go as preferred media for health information seeking (Figure 7).

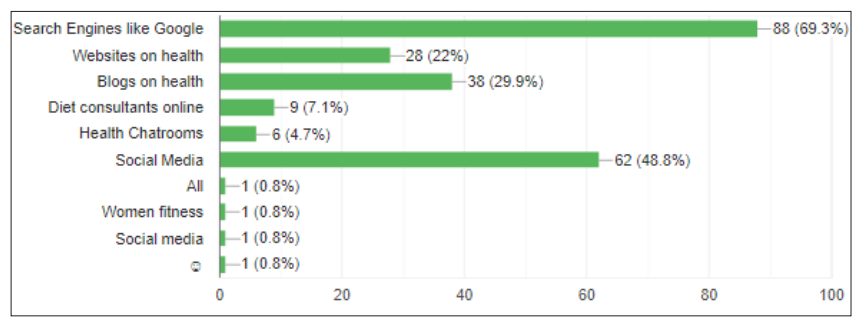

$\mathrm{N}=127$

Figure 8.Online health information platforms accessed/consumed by the respondent

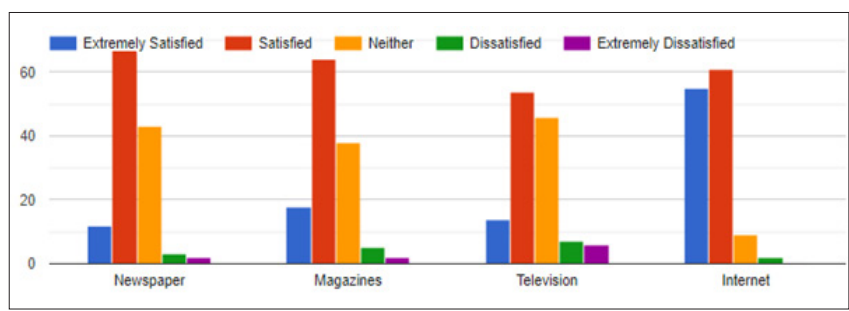

$\mathrm{N}=127$

Figure 9. Respondent satisfaction with the health information accessed/consumed
The google search engine was found to be the most popular way of finding sites related to health indicating that no one site or platform could be identified as a preferred site for health information (Figure 8). The popularity of social media is another cause for concern, unless they follow known experts. Blogs on health and health-related websites are also accessed online.

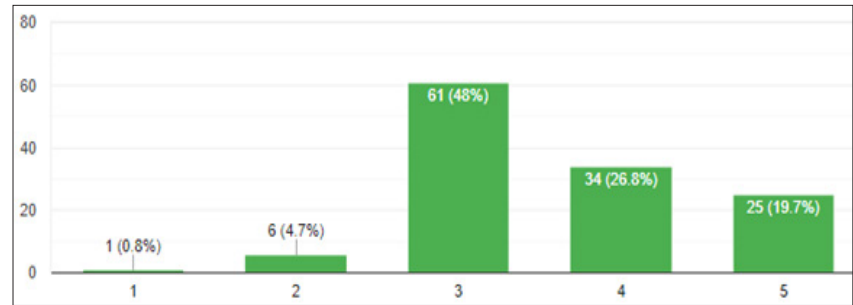

$\mathrm{N}=127$

Figure 10. Agreement with the statement that health information has influenced the respondent's values and beliefs regarding health in a positive way

More than 50 respondents were extremely satisfied and 60 of them were satisfied with health information they got on the internet. With internet being inundated with information on various fields including health, it is important to be able to identify credible and authentic sources. It is no surprise that more than 60 respondents each were satisfied with the heath information provided in newspaper and the magazine, generally known for credibility. The Internet gains a combined satisfaction level of more than 110 respondents. Very few wer dissatisfied with the Internet (Figure 9).

Positive changes in health attitudes and beliefs due to health information consumption in media are not acknowledged by most respondents. $48 \%$ neither agree nor disagree that health information has influenced their values and beliefs regarding health in a positive way. The number of those who disagree and strongly disagree $(26.8 \%$ and $19.7 \%$ respectively) far outnumber those who agree and strongly agree (5.3\% together) (Figure 10 ).

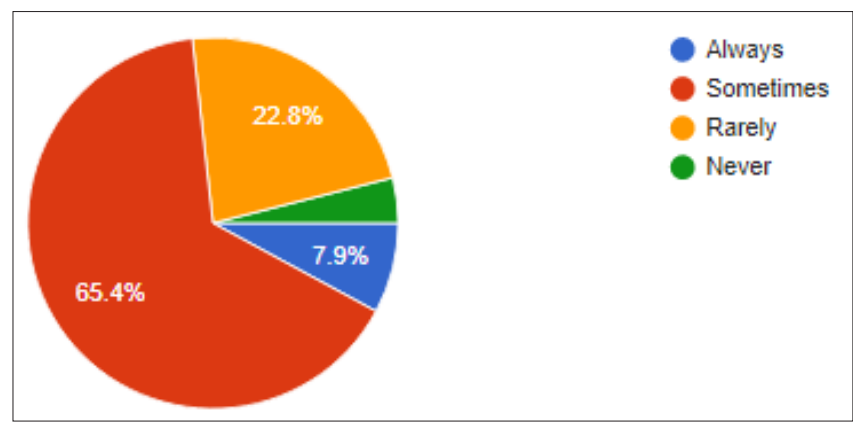

$\mathrm{N}=127$

Figure 11. Application of health information/ instruction consumed

A large number (65.4\%) acknowledged that they did follow instructions sometimes, and $7.9 \%$ always. $22.8 \%$ rarely 
followed health information gained through media. While media may not have changed attitudes and beliefs regarding health positively for most, behavioral response in terms of application is quite high (Figure 11).

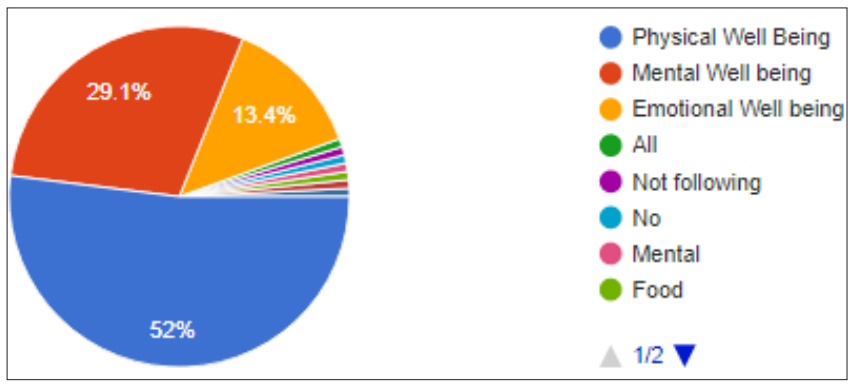

$\mathrm{N}=127$

Figure 12. Areas of health information accessed that is applied by respondent

Among those who had behavioural response, much of the information applied was that of physical wellbeing (52\%), followed by mental and emotional wellbeing (29.1\% and 13.4\%, respectively) (Figure 12 ).

\section{Discussion}

The Internet revolution has primarily bridged two opposing theories: while its ubiquitous presence that has dramatically changed the way we communicate supports the main tenets of the technological determinism theory, the unprecedented way in which people have accepted the new media technology and made it their own is an unquestionable evidence of social shaping of technology. Indeed the very information owes its origin to this acceptance of a new technology and the versatile ways in which people use it. Studies have shown that the Internet is the most preferred source for health information seeking among young adults today. The study also supports the research findings. The advantages of accessing health information on the Internet are manifold as it is possible to overcome spatial and temporal barriers by allowing individuals to obtain information 24/7. Other positive aspects are the possibility to exchange experiences and express opinions in an anonymous setting without feeling judged, and the opportunity to find social support from virtual communities.

With a plethora of medical information, individuals take a more active role in managing their personal health, it is essential for scholars to better understand the general public's information-seeking behaviour. ${ }^{5}$ This is evident from the study.

The researcher found Flora et al. ${ }^{6}$ observe that the media seem to hold the potential for profound influences on health at many levels of audience organization. However, the media constitutes only one set of intervention strategies. The impact of media, both mass and narrowcast media, can be intensified and extended when combined with other forms of intervention.

Bou-Karroum et al. suggest that media interventions may have a positive impact when used as accountability tool leading to prioritizing and initiating policy discussions, increase policymakers' awareness, influence policy formulation, as awareness tools leading to policy adoption. ${ }^{7}$

Renganathan L, Ray S, Nagpal D in their study pointed out that the relationship between Doctors and Patients was changing due to increased use of Internet as a health information resource. They propose that the doctors should also be Internet savvy and should be aware of sources of information and thus build confidence in todays Patients, paving healthy relationships. ${ }^{8}$

Bakar surveyed information seeking behaviors of rural women in Malaysia. The purpose of this study was to identify the women's information needs, determine the information sources used by rural women in a village of the District of 7 Gombak, in the State of Selangor, to determine their information seeking behaviors and identify any access barriers to those sources of information. He concluded that the women depend mostly on mass media such as newspapers, magazines, television and radio for information on health. It is most likely that they choose the popular magazines which have some sections on health information. At least 10\% recorded the use of Internet for accessing health information and most of the housewives use the relevant websites or homepages to get the needed information. Women also consulted other sources such as family and friends. ${ }^{9}$

The researcher found that mobile apps were far behing print and google search engine as the preferred source of healthcare information. In the study, Media Use for Health Information Dissemination to Rural Communities by Ghana Health Service, Philippa Pascalina observed that while Print was the primary medium, mobile technology for community health could be effective and recommend that exploring potential mechanism for monitoring quality health communication using new media is an area of research. ${ }^{10}$

In a study Anand et al highlight how social networking provides cost-effective platforms to communicate with large population. ${ }^{11}$

Another study emphasises the emergence of social media as a new dimension to communication-encompassing all aspects of human endeavour and highlight the strategies that could enhance the value of social media for behaviour change communication. ${ }^{12}$. Hence the current context social media becomes an important tool of dissemination of health messages.

Thus the literature reviewed supports the findings of the current study. 


\section{Conclusion}

Several theories and perspectives uncovered the multidimensional nature of the audience, their expectations from the media, how they used it and what satisfaction they got from this use. Competition among media for a share of the audience resulted in a greater impetus on audience research.

Hence from the study it is evident that:

- Media consumption patterns of young adults pertaining to health are primarily dependent on Internet.

- The main areas of search pertaining to health are related to health fitness specifically physical health.

- The various platforms that are most commonly accessed for health information are Google, Blogs and social media.

- The existing health related values and beliefs are affected by the online media.

Application of the health information consumed.

Social influence, social comparison, and convergence theories proposed by social scientists specify that one's perception and behaviour are influenced by the perceptions and behaviours of the members of groups to which one belongs. Peer group influences and social influences such as those presented through television and radio can affect the process of change and eventual conversion of behaviour.

While authenticity of health information online is a cause for concern, a large number of respondents are satisfied with health information consumed online. Most of them however, do not find a positive change in health-related values and beliefs by consuming health information on media in general. It is also interesting to note that more than $50 \%$ do follow the health instructions/information consumed by them. This points out to two important factors: one, a need for stronger, persuasive messages in the media regarding the importance of having high health related values and beliefs; and two, the role that other communication modes- interpersonal communication especially with health experts, and family communication is all the more important in this area.

\section{Limitations of the Study}

Respondents are predominantly females in the age group 17 to 19 years. More pilot studies need to be done to study male respondents and higher age groups also.

\section{Conflicts of Interest: None \\ References}

1. World Health Organisation Consolidated ARV guidelines, (June 2013).

2. Lambert \& Loiselle, 2007; Mills \& Todorova, 2016, Qualitative Health Research, 10.1177/1049732307305
199, 01/11/2007 Vol 17.

3. Ovarec JA. On-line medical information and service delivery:implications for health education. J Health Educ 2000; 31: 105-110.

4. Wartella E, Rideout V, Montague H, Beaudoin-Ryan L, Lauricella A. Teens, Health and Technology, a national survey conducted by the Center on Media and Human Development at Northwestern University.

5. Jacobs W, Ann O. Amuta, Jeon CK, Alvares C. Health information seeking in the digital age: An analysis of health information seeking behavior among US adults. Cogent Social Sciences 2017; 3:1. DOI: 10.108 0/23311886.2017.1302785.

6. JA Flora, Edward W, Maccoby N. The Role of Media across Four levels of Heath Promotion Intervention. Annu Rev Public Health 1989; 10: 181-201.

7. Bou-Karroum L, El-Jardali F, Hemadi N. Using media to impact health policy-making: an integrative systematic review. Implementation Sci 2017; 12(52). DOI:10.1186/ s13012-017-0581-0.

8. Renganathan L, Ray S, Nagpal D. Use of internet for accessing healthcare information among patients in an outpatient department of a Tertiary Care Center. $J$ Mar Med Soc 2017; 19: 15-17.

9. Bakar. Information Seeking Behaviours of Rural Women in Malaysia. Libraries at University of Nebraska-Lincoln Library Philosophy and Practice (e-journal) 2011.

10. Pascalina P. Media Use for Health Information Assemination to Rural Communities by Ghana Health Service. Journal of Information Science Systems and Technology 2018.

11. Sweta Anand Mayukta Gupta et al. Social media and effective health communication. Journal of Social Science and Interdisciplinary Research 2013; 2.

12. Olarunlekein E. Behaviour change Communication Using Social Media a Review. International Journal of Communication and Health 2016. 